\title{
Tensile Instability in a Hydrogenated Low Alloy Steel
}

\section{B. SASMAL and S. K. SINGH ${ }^{11}$}

Department of Metallurgical and Materials Engineering, Indian Institute of Technology, Kharagpur-721302, India. E-mail: sasmal@hijli.iitkgp.ernet.in 1) Formerly Department of Metallurgical and Materials Engineering, Indian Institute of Technology. Now at Department of Metallurgical Engineering, Bihar Institute of Technology, Sindhri, India.

(Received on June 2, 1997; accepted in final form on October 30, 1997)

\begin{abstract}
Sheet tensile specimens prepared from a cold rolled low alloy steel were annealed at $700^{\circ} \mathrm{C}$ to get equiaxed ferrite grains of $8,21.5$ and $32.5 \mu \mathrm{m}$ diameters other than spheroidal carbides and inclusions, charged cathodically in $1 \mathrm{~N} \mathrm{NaOH}$ and $0.1 \mathrm{~N} \mathrm{H}_{2} \mathrm{SO}_{4}$ solutions with a current density of $50 \mathrm{~mA} / \mathrm{cm}^{2}$ and tested in a hard beam tensile testing machine at a slow strain rate. Fracture characteristics were studied in SEM. By comparing the values of $\sigma$ at the point of intersection of computed $\sigma v s, \varepsilon$ and $d \sigma / d \varepsilon v s$. $\varepsilon$ curves with the actual values corresponding to UTS a measure of the enhancement of plastic instability by hydrogen was obtained. It has been found that the higher the hydrogen content the lower are the values of stress and strain at which plastic instability was initiated, and the higher the ferrite grain size the greater is the enhancement of this instability. These effects have been discussed in the light of viewed fracture modes.
\end{abstract}

KEY WORDS: tensile instability; cathodic charging; low alloy steel.

\section{Introduction}

It is well known that hydrogen changes mechanical properties of steels in various ways. Soluble hydrogen promotes instability in plastic flow in steels. Lee et al., ${ }^{1)}$ in their studies of precharged spheroidised 1090 steel by bend test, found hydrogen to promote the onset of plastic instability in two ways: (1) by the formation of concentrated shear along characteristic slip traces and propagation of these shear instability bands at a given load, in contrast to uniform flow in the absence of hydrogen, and (2) by the formation of multiple Luders bands and continuation of their formation ahead of propagating bands, in contrast to propagation of a single Luders band in the absence of hydrogen. Multiple criss-cross Luders bands formation in the presence of hydrogen has also been reported by Oriani and Josephic $^{2,3)}$ in spheroidised and pearlitic steels. Lin and Oriani $^{4)}$ found hydrogen to suppress the onset of shear localisation at low and medium input fugacities but to enhance it at very high input fugacities, in plane-strain bend specimens. They suggested that the strain for plastic instability increased with hydrogen charging current density until currents near those for irreversible damage were achieved.

Hydrogen also enhances the instability in plastic flow by the formation of microvoids. ${ }^{4-7)}$ In plane-strain bend tests, indirect observations of microvoids aligned along characteristic slip traces, ${ }^{6}$ the association of void configuration . with plastic shear incompatibility stresses, ${ }^{6}$ and observations of surface instabilities ${ }^{8)}$ and of shear crack initiation, ${ }^{6,8)}$ all have indicated that hydrogen enhances the tendency for plastic instability. The effects are not only sensitive to metallurgical variables such as composition, microstructure, impurity level and processing history but also to other variables such as strength level, load level, type of loading, strain rate, type of charging and charging current density.

Although some of the reported results are seemingly inconsistent with one another, the critical plastic strain for unstable flow was, in general, lowered by the influence of hydrogen. No attempt, however, was made in these works to measure the effect of hydrogen on the initiation of unstable plastic flow quantitatively. In the present paper a quantitative estimation of the influence of hydrogen on the instability in plastic flow of a low alloy steel under tension has been presented by comparing the computed point of instability with its actual value corresponding to UTS.

\section{Experimental}

Steel plates of $5 \mathrm{~mm}$ in thickness having $0.1 \mathrm{C}, 0.25$ $\mathrm{Si}, 0.87 \mathrm{Mn}, 0.56 \mathrm{Cr}, 0.47 \mathrm{Ni}, 0.21 \mathrm{Mo}, 0.023 \mathrm{~S}$ and $0.013 \mathrm{P}$ expressed in mass $\%$, were cold rolled to a thickness of $1.6 \mathrm{~mm}$. Tensile specimens of the dimensions as shown in Fig. 1, prepared from these rolled sheets were recrystallised at $700^{\circ} \mathrm{C}$ for 24,72 and $120 \mathrm{~h}$ to get different grain sizes of ferrite. To prevent oxidation specimens were annealed under used charcoal cover and then cooled in air. Heat treated specimens were ground on emery papers in order to make the surface free from any artifacts and to get a uniform thickness of $1.5 \mathrm{~mm}$. Ferrite grain size was measured by using intercept method. ${ }^{9)}$

Clean tensile specimens were charged cathodically in a low fugacity $1 \mathrm{~N} \mathrm{NaOH}$ and a medium fugacity $0.1 \mathrm{~N}$ 


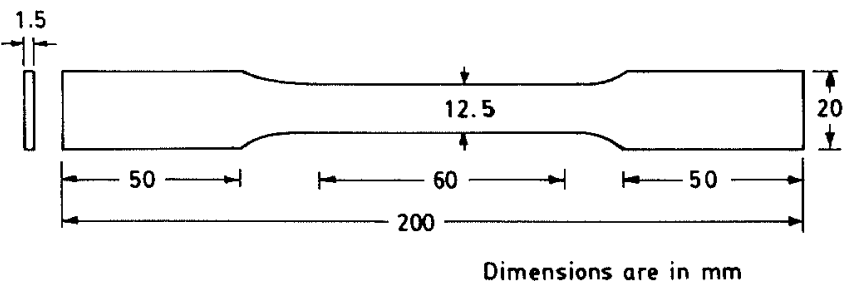

Fig. 1. Dimensions of tensile specimens.

$\mathrm{H}_{2} \mathrm{SO}_{4}$ electrolytes for periods varying from 2 to $24 \mathrm{~h}$. Electrolytes were poisoned by adding $5 \mathrm{mg}$ of $\mathrm{As}_{2} \mathrm{O}_{3}$ per litre in order to prevent recombination of evolving hydrogen atoms during charging. Anodes were placed on both sides of the specimens. Lead sheet pieces were used as anodes in $0.1 \mathrm{~N} \mathrm{H}_{2} \mathrm{SO}_{4}$ and graphite pieces in $1 \mathrm{~N} \mathrm{NaOH}$ electrolyte. A current density of $50 \mathrm{~mA} / \mathrm{cm}^{2}$ was maintained for each charging operation. After charging specimens were cleaned under running water and immediately preserved in liquid nitrogen until the tensile testing started.

Tensile tests were carried out in a screw type hard beam tensile testing machine at a slow strain rate (cross-head velocity, $1.2 \mathrm{~mm} / \mathrm{min}$ ), and load-elongation curves were plotted on a strip chart recorder. Testing was repeated at least for three specimens which were heat treated and charged under identical conditions. Fractured specimens were preserved in a vacuum dessicator and as soon as possible the fractured surfaces were examined in a SEM.

To find hydrogen content of the charged specimens a set of specimens having dimensions $60 \mathrm{~mm} \times 12.5 \mathrm{~mm} \times$ $1.5 \mathrm{~mm}$ were prepared from the sheets which were cold rolled and recrystallised as mentioned earlier. These specimens were charged cathodically in the identical conditions as mentioned for the tensile specimens. After completion of charging the specimens were washed and preserved in liquid nitrogen until the start of analysis. Just before the start of analysis the specimen was cut into small pieces as only less than $1 \mathrm{gm}$ of the specimen was required for one analysis. LECO RH-2 Hydrogen Determinator was used for this analysis. This analysis was done for all the specimens having microstructures and charging conditions identical to those of the tensile specimens, and for a particular specimen the analysis was repeated at least for three times.

\section{Basis of Computation}

Instability in deformation under tension in metals and alloys occurs when the increase in stress due to the decrease in cross-sectional area of a specimen becomes greater than the increase in load-carrying ability of the metal due to strain hardening. This condition of instability leading to localised deformation is defined by the condition $d P=0$, where $P$ is the applied load. From this condition it may be shown ${ }^{10)}$ that at a point of tensile instability,

$$
d \sigma / d \varepsilon=\sigma
$$

where $\sigma$ is the true stress and $\varepsilon$ is the true strain. Thus

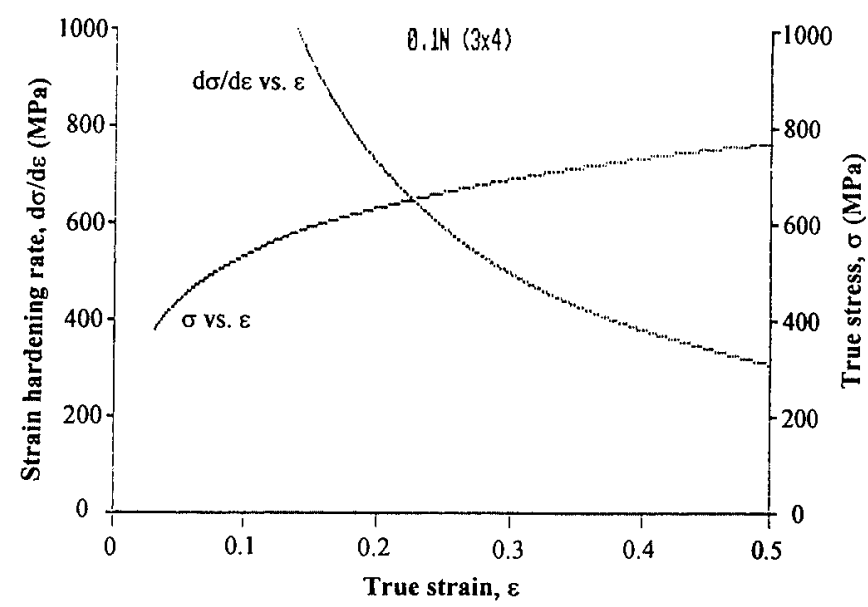

Fig. 2. Computed $d \sigma / d \varepsilon v s$. $\varepsilon$ and $\sigma$ vs. $\varepsilon$ plots for a specimen recrystallised for $72 \mathrm{~h}$ at $700^{\circ} \mathrm{C}$ and charged for $4 \mathrm{~h}$ in $0.1 \mathrm{~N} \mathrm{H}_{2} \mathrm{SO}_{4}$ solution.

the point of instability corresponding to the start of necking at the maximum load can be obtained from the $\sigma v s . \varepsilon$ curve by finding its point of intersection with the curve $d \sigma / d \varepsilon$ vs. $\varepsilon$, i.e., where $d \sigma / d \varepsilon=\sigma$.

From the obtained load-elongation curve for a particular tensile specimen the values of load and the corresponding elongation were noted at certain interval of elongation in the uniform plastic deformation region of the specimen. From these data, the values of $\sigma$ and corresponding $\varepsilon$, and $\sigma v s . \varepsilon$ and $d \sigma / d \varepsilon v s . \varepsilon$ curves were computed with a BASIC programme. $\sigma$ vs. $\varepsilon$ and $d \sigma / d \varepsilon$ vs. $\varepsilon$ curves were computed based on the portion of a load-elongation curve, from the end of yield point elongation prior to the attainment of maximum load, and extrapolated beyond the point of their intersection. A representative plot is shown in Fig. 2. The computed value of stress at the point of plastic instability for a specimen was obtained from the point of intersection of these curves as shown in Fig. 2 as an example.

\section{Results}

\subsection{Microstructure of the Heat Treated Specimens}

Microstructure of the heat treated samples consisted of recrystallised ferrite grains with a random distribution of spheroidal carbides and a few inclusions (Fig. 3). The carbide particles have been identified to be cementite by electron diffraction patterns. The average ferrite grain diameter, on recrystallisation for 24,72 and $120 \mathrm{~h}$ at $700^{\circ} \mathrm{C}$, was measured to be $8,21.5$ and $32.5 \mu \mathrm{m}$ respectively.

\subsection{Surface Appearance of the Cathodically Charged Specimens}

Appearance of the specimen surface for all the periods of charging in $1 \mathrm{~N} \mathrm{NaOH}$ solution was found to be as clean as before the charging. After longer periods of charging in $0.1 \mathrm{~N} \mathrm{H}_{2} \mathrm{SO}_{4}$ solution the specimen surface was found to be tarnished to some extent. Possibly, this is due to the deposition of arsenic oxide and antimony oxide at the specimen surface. The loosely adhered coating was washed away easily with water after com- 


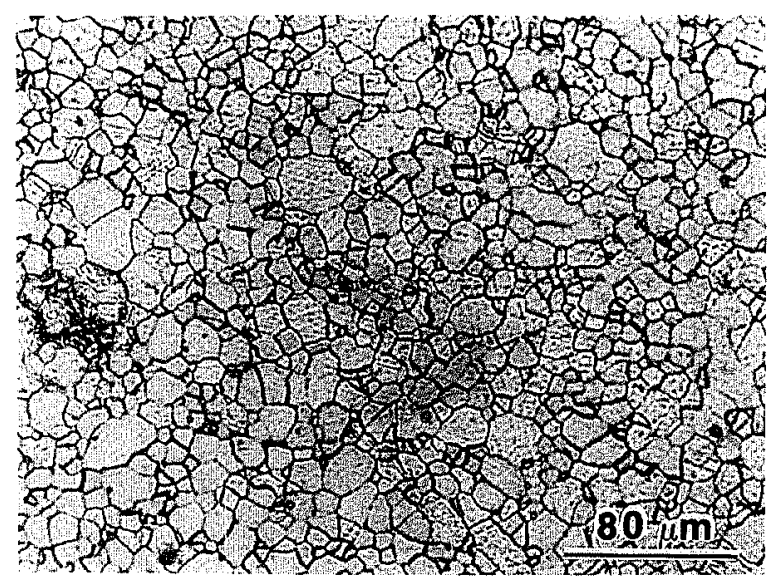

Fig. 3. Microstructure of a specimen recrystallised for $72 \mathrm{~h}$ at $700^{\circ} \mathrm{C}$.

pletion of charging. The source of antimony is the commercial lead which was employed as anodes in the charging cells. Longer periods (16 and $24 \mathrm{~h}$ ) of charging in $0.1 \mathrm{~N} \mathrm{H}_{2} \mathrm{SO}_{4}$ also produced a few small blisters at the specimen surface. Specimens of larger ferrite grain size had more blister formation, both size and numberwise, for a particular charging period.

\subsection{Hydrogen Content of the Charged Specimens}

Analysis by LECO RH-2 Hydrogen Determinator showed some variation in hydrogen content of the specimens which were treated and charged under identical conditions. Average values of at least three analyses of identically treated specimens showed a linear increase in hydrogen content of the specimens with the increase in period of charging in both the electrolytes. Increase in charging period from 2 to $24 \mathrm{~h}$ in $1 \mathrm{~N} \mathrm{NaOH}$ solution caused the hydrogen content to vary from 6.5 to $17.5 \mathrm{ppm}$. The results indicated that there was no appreciable difference in hydrogen content of the specimens of different ferrite grain sizes for any of the charging periods in this electrolyte.

Charging in $0.1 \mathrm{~N} \mathrm{H}_{2} \mathrm{SO}_{4}$ solution for the shorter periods caused little difference in hydrogen content of the specimens of all the ferrite grain sizes. However, longer periods of charging caused a slightly higher hydrogen content in the specimens of smaller ferrite grains. For $24 \mathrm{~h}$ of charging the specimens of $8,21.5$ and $32.5 \mu \mathrm{m}$ ferrite grain sizes showed a difference in hydrogen content by about $1.5 \mathrm{ppm}$. Hydrogen content of the specimens of the medium ferrite grain size changed from 10 to $26 \mathrm{ppm}$ on increasing the period of charging from 2 to $24 \mathrm{~h}$.

\subsection{Tensile Properties}

A prominent yield point elongation was noted in all the specimens, charged as well as uncharged. The load at the yield point has been considered to be the average load at the yield point elongation zone.

In the uncharged condition yield stress, ultimate tensile stress and \% elongation were higher in the specimens of smaller ferrite grain size. The nature of load-elongation curves of the steel changed with the increase in hydrogen content corresponding to different charging conditions.

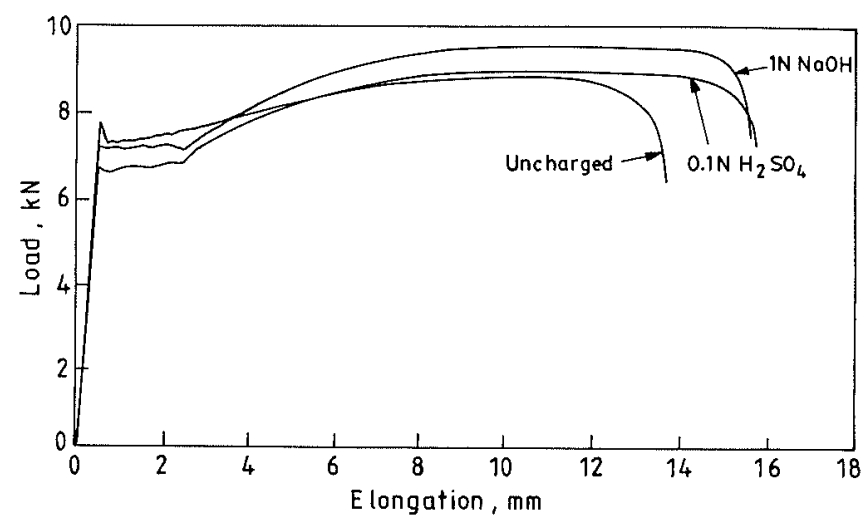

Fig. 4. Load-elongation diagrams of tensile specimens recrystallised for $72 \mathrm{~h}$ at $700^{\circ} \mathrm{C}$ and charged for $4 \mathrm{~h}$ in the electrolytes.

A set of load-elongation curves is shown in Fig. 4. Increase in hydrogen was associated with a decrease in yield stress and increase in UTS and \% elongation. UTS and $\%$ elongation, however, declined after attaining peak values with the further increase in hydrogen content. ${ }^{11}$ These changes in tensile properties, again, had some dependence on the grain size of ferrite. Serration and stepwise deformation were noted in the load-elongation curves of the specimens charged for longer periods in $0.1 \mathrm{~N} \mathrm{H}_{2} \mathrm{SO}_{4}$ solution. In these specimens a good amount of deformation occurred with little change in the applied load till the fracture. Details of the change in tensile properties ${ }^{11)}$ will be reported in a separate publication.

Uncharged specimens showed a good amount of necking prior to fracture. Extent of necking, however, reduced with the increase in hydrogen content, and in the specimens charged for longer periods in $0.1 \mathrm{~N} \mathrm{H}_{2} \mathrm{SO}_{4}$ solution necking was not so preminent.

\subsection{Tensile Instability}

The values of true stress $\sigma$ and true strain $\varepsilon$ corresponding to UTS/maximum load in the load-elongation curve, for each specimen charged as well as uncharged, were calculated. The average values of these true stress and true strain for the specimens having identical treatments are considered as the actual values of stress and strain when the instability in plastic flow started in the specimen of a particular treatment.

$\sigma$ vs. $\varepsilon$ and $d \sigma / d \varepsilon$ vs. $\varepsilon$ curves were computed for each specimen on the basis of initial portion of plastic region of the load-elongation curve (prior to maximum load) and extrapolated to get intersection of these curves, as stated earlier. The value of true stress at the point of intersection of these curves for each specimen is noted. The average value of this true stress for the specimens of identical treatments is taken as the value of computed stress for the initiation of plastic instability in the specimen of a particular treatment.

For uncharged specimens the actual values of stress at the point of plastic instability (maximum load) match well with those of stress at the computed point of instability. But the actual values of this stress for the charged specimens are less than the computed values. This difference in the corresponding values of stress 


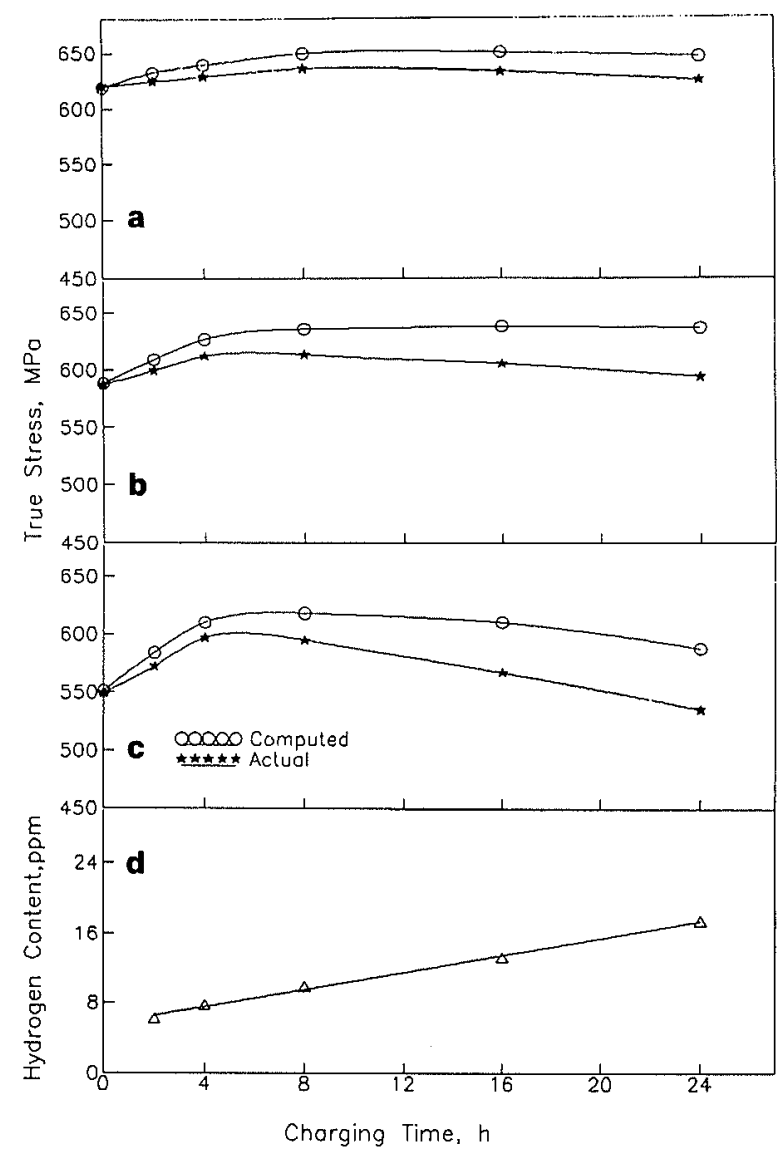

Fig. 5. Difference in the computed and actual values of true stress at the point of tensile instability with hydrogen content corresponding to the time of charging in $1 \mathrm{~N}$ $\mathrm{NaOH}$ for specimens recrystallised at $700^{\circ} \mathrm{C}$ for (a) $24 \mathrm{~h}$, (b) \& (d) $72 \mathrm{~h}$ and (c) $120 \mathrm{~h}$.

increases with the increase in hydrogen content of the specimens as a result of the increase in charging time for each of the electrolytes used, as shown in Figs. 5 and 6. The difference is remarkable for the specimens charged in the solution of higher hydrogen fugacity, $0.1 \mathrm{~N} \mathrm{H}_{2} \mathrm{SO}_{4}$, specially for longer periods (Fig. 6). In these figures, it may also be noted that for a particular charging condition this difference is larger for the specimens of larger ferrite grain size. Thus plastic instability of the steel studied is enhanced by hydrogen. This is initiated at a lower applied stress associated with a lower strain in a specimen in the presence of hydrogen, and the effect is greater in the specimens of larger ferrite grain size.

In Figs. 5 and 6 the difference in the values of actual and computed stresses at the point of plastic instability of a specimen has been shown against the hydrogen content of specimens of the medium ferrite grain size only. This has been done for a simplified presentation and would not be unjustified because of no appreciable difference in hydrogen content of the specimens of different ferrite grain sizes except those charged for longer periods in $0.1 \mathrm{~N} \mathrm{H}_{2} \mathrm{SO}_{4}$, and even for these longer charging conditions the difference in hydrogen content with the ferrite grain sizes is small.

\subsection{Fracture Characteristics}

Examination of fractured surfaces revealed the fracture

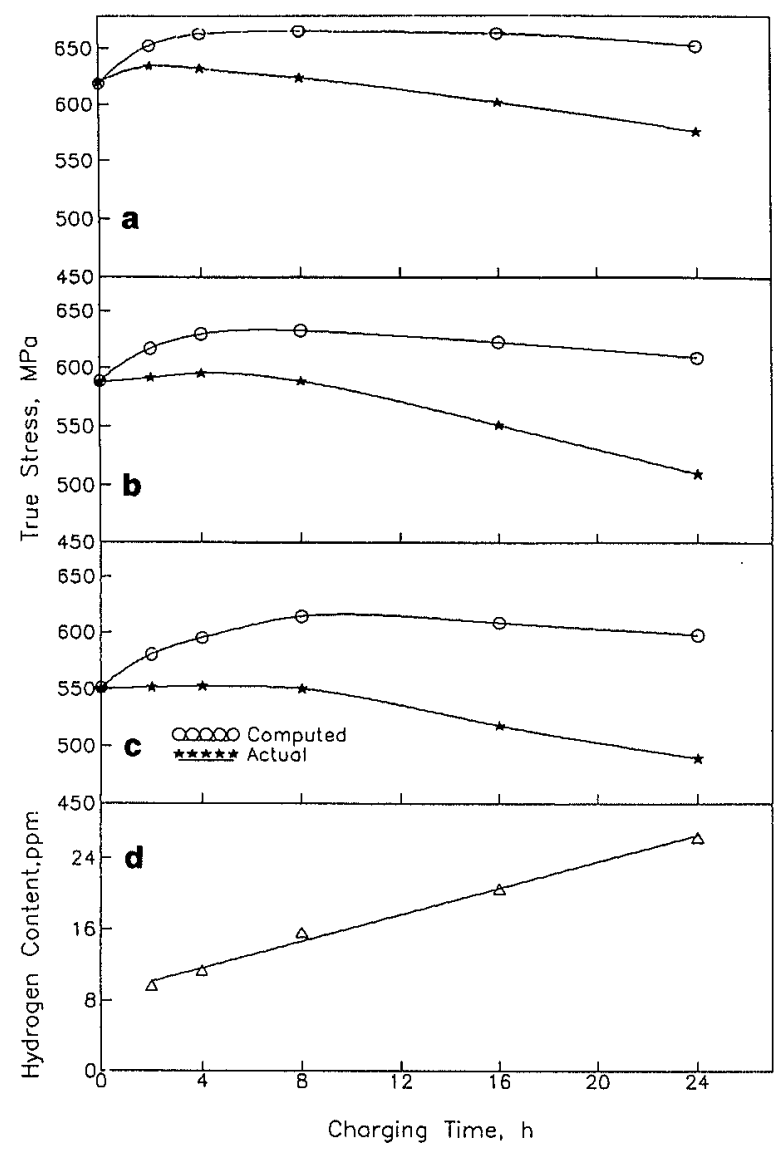

Fig. 6. Difference in the computed and actual values of true stress at the point of tensile instability with hydrogen content corresponding to the time of charging in $0.1 \mathrm{~N}$ $\mathrm{H}_{2} \mathrm{SO}_{4}$ for specimens recrystallised at $700^{\circ} \mathrm{C}$ for (a) $24 \mathrm{~h}$, (b) \& (d) $72 \mathrm{~h}$ and (c) $120 \mathrm{~h}$.

mode in the uncharged specimens to be highly ductile characterised by the formation of large dimples and tearing of the regions in between dimples. In the charged specimens fracture modes were also dominantly ductile in nature although a gradual change in the fracture characteristics with the increase in hydrogen content was noted. Microvoids formed in the tear zones around well-developed dimples (Fig. 7) and small regions of quasi-cleavage mode of fracture appeared (Fig. 8). On prolonged charging in $0.1 \mathrm{~N} \mathrm{H}_{2} \mathrm{SO}_{4}$ solution the fracture was characterised by the formation of only a few welldeveloped dimples, more uniform distribution of decohesion microvoids and a few quasi cleavage regions. Details of the fracture characteristics ${ }^{11)}$ will be reported in a separate publication.

\section{Discussion}

The computed data in Figs. 5 and 6 represent the extrapolated values of true stress, corresponding to UTS, based on the initial portions of flow curves where no sudden deterioration of tensile properties had occurred in the specimens. Although for uncharged specimens there is little difference between the actual and computed values of this true stress (corresponding to UTS), a gradual decrease in the actual values compared to the computed values with the increase in charging time of 


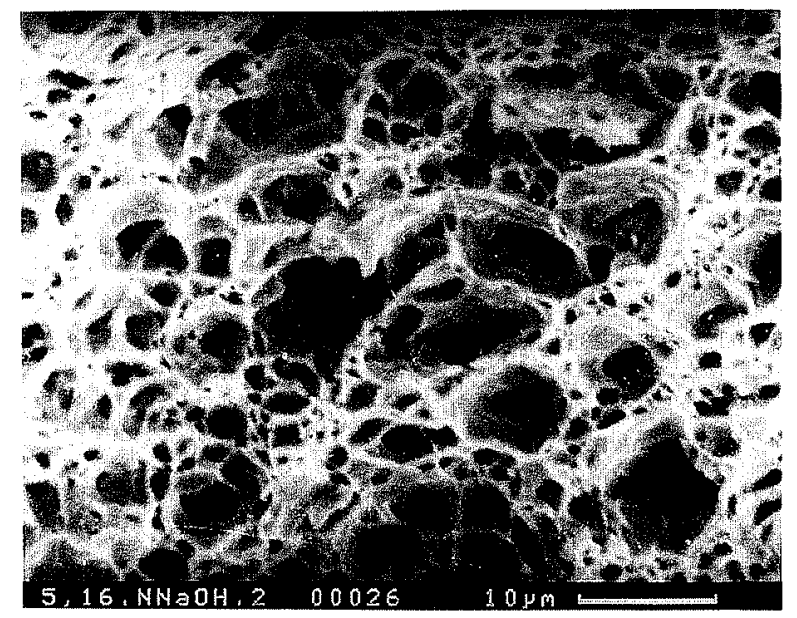

Fig. 7. SEM fractograph of a specimen recrystallised for $120 \mathrm{~h}$ at $700^{\circ} \mathrm{C}$ and charged for $16 \mathrm{~h}$ in $1 \mathrm{~N} \mathrm{NaOH}$ solution.

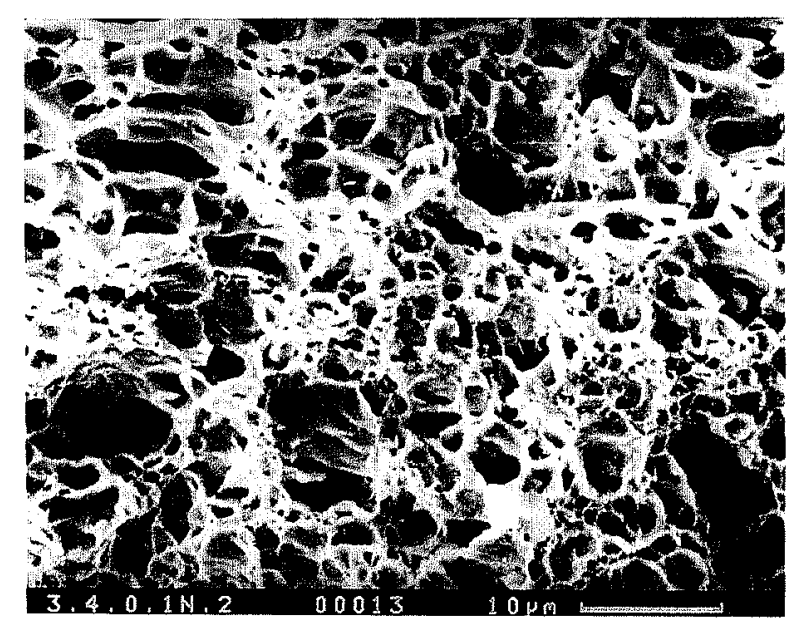

Fig. 8. SEM fractograph of a specimen recrystallised for $72 \mathrm{~h}$ at $700^{\circ} \mathrm{C}$ and charged for $4 \mathrm{~h}$ in $0.1 \mathrm{~N} \mathrm{H}_{2} \mathrm{SO}_{4}$ solution.

the specimens indicates that hydrogen enhances the tendency of the steel for plastic instability, which is characterised by lowering in the values of critical stress and critical strain for the initiation of unstable flow. Obviously hydrogen causes some damage in the steel, which induces a deterioration in tensile strength. Figures 5 and 6 indicate that the larger the hydrogen content the greater is the susceptibility of the steel to this damage being induced at a lower applied stress. Moreover, the observations of no immediate remarkable decrease in load after the attainment of maximum load in a loadelongation curve and the associated small reduction in area in the failed specimens lead to suggest that the damage spreads over a large volume of a specimen and the effect is continued over a large strain.

The presence of a random distribution of spheroidal carbide particles and inclusions in the ferrite matrix influenced the fracture modes by formation of dimples. In the presence of hydrogen decohesion microvoids formed at the interdimple regions. With the increase in hydrogen content dimple size decreased, and number density of microvoids and quasi-cleavage regions in- creased. It is well known that in the presence of second phase particles dimple formation is initiated by decohesion along a particle/matrix interface ${ }^{12-16)}$ when stress around a particle exceeds a critical value. This stress is the sum of (i) the interfacial stress acting on a particle caused by plastic misfit across the particle interface, (ii) the contribution of local strain hardening after plastic relaxation processes around the particle, and (iii) the triaxial stress after necking modified by the void volume fraction. ${ }^{16)}$ In the presence of hydrogen, because of high mobility and multiplication of dislocations ${ }^{17-20}$ the first and second terms of the built-up stress around a particle are expected to attain high values for a comparatively lower applied stress. As a result dimples, in the presence of carbide particles, are expected to be nucleated at a lower applied stress, consistent with the suggestion made by earlier investigators. ${ }^{21,22)}$ Since nucleated at a lower applied stress, these voids are expected to develop over a comparatively larger volume of a specimen and the extent of this microstructural damage increases with increasing plastic strain. ${ }^{23}$ )

Since the formation of dimples is initiated at a lower stress strain hardening characteristics of the steel is affected by this damage effect and plastic instability starts at a lower applied stress. During the growth of these dimples the stress concentration built-up at the interdimple matrix is relaxed by the formation of decohesion microvoids. As this might occur over a large volume of a specimen and triaxial stress might be modified by the formation of these decohesion microvoids extensive necking could not occur although plastic instability had been initiated at a comparatively lower applied stress. This is consistent with the observed small reduction in area in the specimens charged for longer periods. Moreover, in the presence of hydrogen, a change in the active slip systems ${ }^{24)}$ due to increased applied stress might also influence the strain hardening tendency of the steel. The observed serrated flow in the load-elongation curves for specimens charged for longer periods in $0.1 \mathrm{~N} \mathrm{H}_{2} \mathrm{SO}_{4}$ solution was possibly because of shear instability due to block slipping and activation of different slip systems $s^{2,3,24)}$ in the presence of a high concentration of hydrogen.

Higher hydrogen contents, however, induced an embrittling effect in the steel, characterised by the development of quasi-cleavage mode of fracture at isolated sites, while the overall fracture remained predominantly ductile in nature. Possibly this occurred in the regions where the amount of trapped hydrogen had exceeded a critical value. These quasi-cleavage regions might have developed either simultaneously or prior to the initiation of dimple formation elsewhere and had definitely annulled the strain hardening effect of the steel with an apparent effect on the plastic instability.

For a particular charging condition hydrogen intake into a specimen depends upon the rate of absorption at the surface and the rate of diffusion into the bulk. Microstructural features of all the specimens studied were identical except a difference in ferrite grain size. Consequently, preferential trapping sites other than ferrite grain boundaries remained the same in all the 
specimens. Assuming that the hydrogen trap density at ferrite grain boundaries maintains a certain ratio to the grain body hydrogen concentration an increase in the ferrite grain size would lead to an increase in the grain body concentration of hydrogen. Since fracture had occurred only by transgranular cracking, under the conditions of charging employed in this study, hydrogen had possibly affected the grain body strength to a much larger extent than the grain boundary strength. The observed enhanced plastic instability in the specimens of larger ferrite grains (Figs. 5 and 6) under the same charging conditions may be attributed to the presence of a higher hydrogen concentration inside the ferrite grains.

Diffusivity of hydrogen through grain boundaries is higher than that through ferrite lattice. Inspite of that the amount of hydrogen intake in specimens differing in grain size cannot differ widely unless the rate of overall diffusion is lower than the rate of absorption. In the present study, it seems that during charging in $1 \mathrm{~N} \mathrm{NaOH}$ the rate of diffusion of hydrogen into interior of a specimen was higher than the rate of its absorption at the surface. This resulted in the same hydrogen content in the specimens of all the ferrite grain sizes for a particular charging condition. However, during charging in $0.1 \mathrm{~N} \mathrm{H}_{2} \mathrm{SO}_{4}$ the amount of hydrogen absorbed by a specimen surface was possibly slightly higher than that diffused into the interior. This is apparent from the formation of blisters at the specimen surface. Because of a higher diffusivity through grain boundaries more hydrogen might diffuse into interior of the specimens of smaller ferrite grains due to the availability of a larger grain boundary network extended upto the surface. This effect is prominent for longer charging periods resulting in an appreciably higher hydrogen content in the specimens of smaller grains. Although for a certain period of charging in $0.1 \mathrm{~N} \mathrm{H}_{2} \mathrm{SO}_{4}$ the total hydrogen content was lower in the specimens of larger ferrite grains, tensile instability started at a lower applied stress with an associated wider difference in the values of computed and actual stresses at the point of plastic instability (Fig. 6), possibly because of a higher hydrogen distribution inside the grain body due to the presence of a lower grain boundary area where hydrogen trapping is higher.

\section{Conclusions}

(1) Hydrogen induces plastic instability in the steel at a lower stress and a lower strain; the higher the hydrogen content of the steel the greater is the enhancement of plastic instability.

(2) Enhanced plastic instability in the presence of hydrogen is due to the initiation of dimple formation at a lower applied stress. This enhancement may also be caused by the activation of multiple slip systems and block slipping.

(3) The larger the ferrite grain size the lower is the stress for initiation of plastic instability. This effect is due to the presence of a higher concentration of hydrogen inside ferrite grains because of the availability of a lower grain boundary area in the specimens of larger ferrite grains, even when the total hydrogen content in these specimens is slightly lower compared to that in smaller grained specimens.

\section{Acknowledgements}

The authors greatfully thank Dr. A. Biswas, Director, Usha Scientific Research Institute, Ranchi, who was earlier in the department for his help in developing the computer programme. They are also thankful to late Dr. A. K. Mitra of TISCO, Jamshedpur for his kind help in analysing the hydrogen content of the specimens in TISCO.

\section{REFERENCES}

1) T. D. Lee, T. Goldenberg and J. P. Hirth: Fracture, v-2, ed. by D. M. R. Taplin, Pergamon Press, New York, (1977), 243.

2) R. A. Oriani and P. H. Josephic: Acta Metall, 27 (1979), 997.

3) R. A. Oriani and P. H. Josephic: Metall. Trans., 11A (1980), 1809.

4) J. K. Lin and R. A. Oriani: Acta Metall., 31 (1983), 1071

5) H. Cialone and R. J. Asaro: Metall. Trans, 10A (1979), 367

6) T. D. Lee, T. Goldenberg and J. P. Hirth: Metall. Trans., 10A (1979), 199.

7) H. Cialone and R. J. Asaro: Metall. Trans., 12A (1981), 1373.

8) O. A. Onyewuenyi and J. P. Hirth: Metall. Trans., 14A (1983), 259.

9) E. E. Underwood: Quantitative Stereology, Addison-Wesley Publishing Co., Mass., (1970), 81.

10) G. E. Dieter: Mechanical Metallurgy, International Student Ed. McGraw-Hill, New York, (1981), 329.

11) S. K. Singh: Ph. D. Thesis, Indian Institute of Technology, Kharagpur, India, (1992).

12) J. Gurland: Acta Metall., 20 (1972), 735.

13) M. A. Greenfield and M. Margolin: Metall. Trans., 3 (1972), 2649.

14) A. S. Argon and J. Im: Metall. Trans., 6 (1975), 839.

15) R. H. Van Stone, T. B. Cox, J. R. Low, Jr. and J. A. Psioda: Int Met. Rev., 30 (1985), 157.

16) D. Kwon and R. J. Avaro: Metall. Trans., 21A (1990), 117.

17) T. Tabata and H. K. Birnbaum: Scr. Metall., 17 (I983), 947

18) T. Matsumoto, J. Eastman and H. K. Birnbaum: Scr. Metall., 15 (1981), 1033

19) Y. B. Yang, W. Y. Chu and C. M. Hsiao: Scr. Metall., 19 (1985), 1161

20) P. Rozenak: J. Mater. Sci. Lett., 9 (1990), 627.

21) C. D. Beachem: Metall. Trans., 3 (1972), 437.

22) R. A. Oriani and P. H. Josephic: Scr. Metall., 13 (1979), 469.

23) P. F. Thomason: Ductile Fracture of Metals, Pergamon Press, New York, (1990), 56

24) T. Y. Zhang, W. Y. Chu and C. M. Hsiao: Scr. Metall., 20 (1986), 225 . 